\title{
Tension softening curves of plain concrete
}

\author{
HH Chen ${ }^{1,2}$ and RKL Su ${ }^{2, *}$ \\ ${ }^{1}$ Space Structures Research Center, Guizhou University, Guiyang, China \\ ${ }^{2}$ Department of Civil Engineering, The University of Hong Kong, Hong Kong, PRC
}

\begin{abstract}
The tension softening curves (TSCs) of plain concrete with compressive strengths varying between 40 and 90 MPa were estimated by performing three-point bending tests on pre-notched beams. Crack evolution and full-field deformation in the beams were measured using the electronic speckle pattern interferometry technique. The crack characteristics, including the crack opening displacement profiles, the width of the fracture process zone and the length of the crack, were evaluated. By using a newly developed incremental displacement collocation method, the TSCs of plain concrete were determined. To facilitate the use of TSCs by commercial finite element packages, the estimated TSCs were simplified to bilinear and exponential curves, and the related parameters were determined.
\end{abstract}

Keywords: concrete; electronic speckle pattern interferometry; crack characteristic; fracture process zone; incremental displacement collocation method; tension softening curve; normal strength concrete; high strength concrete 


\section{Introduction}

The fracture property of concrete dominates the fracture failure of concrete structures and is essential for the design and durability assessment of reinforced concrete (RC) structures. It has been studied that concrete shows inelastic fracture behaviour at the tip of the crack due to the presence of the fracture process zone (FPZ) [1]. Researchers are interested in the characteristics of the FPZ so that the role of the FPZ in the fracture behaviour of concrete can be clarified and a constitutive law can be obtained for concrete in the post-cracking stage.

Many efforts have been made in recent decades to characterise the FPZ in concrete in terms of the extent of the FPZ [2-6], the formation and propagation of the FPZ [7-9], size effect of the FPZ $[3,10]$ and other properties of the FPZ [11-15]. Despite countless research efforts on the FPZ, there are still numerous uncertainties, such as the energyconsuming mechanism of the FPZ and the crack advance length, which prevent the establishment of effective fracture mechanics parameters for concrete [16]. Direct observations of the actual crack using a measurement instrument with high reliability and precision are necessary to validate the characteristics of the FPZ experimentally [17]. This paper provides a direct measurement of the FPZ in concrete by using electronic speckle pattern interferometry (ESPI) technique. Crack evolution and fullfield deformation in the beam were measured using the ESPI technique. The crack characteristics including the crack opening displacement (COD) profiles, the width of the FPZ and the crack length were evaluated.

Cohesive crack model (CCM) is usually used to simulate the nonlinear fracture behaviour of concrete. To employ the CCM, the tension softening curve (TSC) is required. A great deal of effort has been made in recent decades to investigate the TSCs of concrete [18-20]. Ideally, the TSC can be derived from a direct uniaxial tensile test 
on the concrete specimen [21-23]. The cohesive stress is calculated from the applied load, while the crack opening is measured by displacement transducers. However, experimental trials showed that it is very difficult to estimate the TSC of concrete using uniaxial tests due to some inherent drawbacks: multiple cracking, asymmetric modes of fracture, and sudden failure of the sample [24]. Alternatively, the TSC can be inferred from an inverse analysis by minimising the difference between the numerical and experimental results using various optimisation algorithms [18, 25, 26]. For most of the inverse analyses, the shape of the TSC was found to be linear [27], bilinear [28, 29], trilinear or exponential. Other studies have performed trials without using a prescribed shape for the TSC, to construct a polylinear softening model [16, 30, 31]. Although optimisation algorithms were utilised in the numerical analysis, ill- conditioned problems were still critical in the inverse analysis. To increase the accuracy of the solution achieved by the inverse analysis, more constraints must be imposed [32]. In this paper, the newly developed incremental displacement collocation method (IDCM) [33] was used to estimate the TSCs of concrete with compressive strengths varying from $40 \mathrm{MPa}$ to $90 \mathrm{MPa}$. The parameters of the TSCs, including the tensile strength $f_{t}$, the characteristic crack opening $w_{c}$, and the fracture energy $G_{F}^{T S C}$, were determined. The estimated TSCs were compared with previously reported results. Furthermore, the estimated TSCs were approximated as bilinear and exponential curves, and the related parameters were determined.

\section{Theoretical background}

\subsection{The CCM}

The CCM has been widely used to simulate the fracture behaviour of quasi-brittle materials. In the CCM, the traction between the crack surfaces follows a cohesive 
constitutive law, namely a TSC. The TSC is typically represented as a stress-crack opening relationship: $\sigma(w)$, where $\sigma$ is the cohesive stress and $w$ is the crack opening in the cohesive zone (Fig. 1). As the crack opening increases, the cohesive stress decreases until it reaches zero. The cohesive stress can be expressed as

$$
\sigma=f(w), \quad 0 \leq w \leq w_{c}
$$

where $f(w)$ represents the TSC to be determined, and $w_{c}$ is the characteristic crack opening at which the cohesive stress reaches zero. The cohesive stress is assumed to be equal to the tensile strength $f_{t}$ when $w=0$.

\subsection{The IDCM}

The IDCM [33] combines the ESPI technique and the finite element method (FEM) to calculate the TSC of quasi-brittle materials. A three-point bending test was performed on pre-notched beams. Full-field displacement of the beams was measured using the ESPI technique. From the ESPI results, precise displacements such as the mid-span deflection $\delta$, the crack mouth opening displacement (CMOD), the notch tip opening displacement (NTOD) and the COD profile were determined. The COD profile was used to predict the cohesive stress in the FPZ. By assigning the cohesive stress into the interfacial elements in the FPZ, FEM can be used to determine the numerical responses of the specimens.

The IDCM allows the TSC to be estimated in a stepwise manner. At each loading step, only one of the cohesive stresses (e.g., $\sigma_{i}$ in Fig. 2a) that form the TSC needs to be evaluated (i.e., the one that gives the correct structural response to the current load, as predicted by the FEM). The other cohesive stresses on the TSC, such as $f_{t}$ and $\sigma_{1}$ to $\sigma_{i-1}$, would have been determined in the previous loading steps. The cohesive stresses in the 
FPZ can be determined from the assumed TSC and the measured COD profile (Fig. 2b). The correct cohesive stress is identified by matching the experimental displacements from the ESPI technique to the numerical displacements from the finite element analysis at a set of collocation points along the FPZ. The parameters estimated by the IDCM include the piecewise-linear relationship of the TSC, the critical crack opening displacement $w_{c}$ and Young's modulus $E$ of the concrete.

Compared with other available methods, the IDCM provides several advantages in improving the accuracy of the solutions. First, the TSC is determined based on a piecewise-linear approximation without a prior assumption on the TSC shape. Thus, more realistic TSC shape can be obtained. Second, both global and local responses of the specimen are considered in the displacement collocation, thereby reducing the extent of ill-posed conditions. Third, the estimated TSC satisfies the displacement requirements at all loading states. For one single loading state, it is not difficult to find a TSC to satisfy the displacement requirements; however, the real TSC reflects the evolution of the crack and should satisfy the displacement requirements at all loading states.

A flow chart of the process for determining the TSC using the IDCM is presented in Fig.

3. The procedures are briefly described below.

(1) Extraction of the experimental displacements

The experimental displacements, including $\delta$, CMOD, NTOD and the COD profile, are used for numerical analysis.

(2) Estimation of $E$

Using the FEM, the Young's modulus $E$ can be determined by matching the calculated and measured displacements in the linear elastic deformation stage. At the early loading 
stages, the $E$ value generally controls the numerical responses of the specimen because the FPZ is relatively short.

(3) Determination of the length of the FPZ

In the COD profile, the positions of the front of the crack and the rear end of the cohesive crack (e.g., the initial notch tip) are identified; thus, the length of the FPZ can be determined. In the FPZ, cohesive stresses will be assigned to the interfacial elements along the crack line.

(4) Calculation of the cohesive stress $\sigma$ in the FPZ

From the COD profile, the crack opening $w(y)$ can be determined at various interfacial nodes in the FPZ of the FEM data set. The $y$ axis is defined along the crack line with the origin at the notch mouth. As shown in Fig. 2a, at the $i^{\text {th }}$ loading step, all of the nodal points on the TSC in the previous $i-1^{\text {th }}$ loading steps would have been defined; only the last step $\left(w_{i}, \sigma_{i}\right)$ needs to be determined using the IDCM. The cohesive stresses at all the interfacial nodes with $w$ less than or equal to $w_{\mathrm{i}-1}$ can then be established. Because the TSC must be a decreasing function, the unknown stress $\sigma_{i}$ should satisfy the following requirement:

$$
\sigma_{i} \leq \sigma_{i-1}
$$

where $\sigma_{i-1}$ is the cohesive stress determined at the $i-1^{\text {th }}$ loading step. For $i=1, \sigma_{0}$ is equal to $f_{t}$, which can be determined by the splitting tension test.

Using linear interpolation, the nodal cohesive stress $\sigma(y)$ at the $j^{\text {th }}$ segment of the TSC can be expressed in terms of the crack opening:

$$
\sigma(y)=\sigma_{j-1}+\frac{\sigma_{j}-\sigma_{j-1}}{w_{j}-w_{j-1}}\left(w(y)-w_{j-1}\right)
$$


where $w(y)$ is the crack opening of the node considered; $\left(w_{j-1}, \sigma_{j-1}\right)$ and $\left(w_{j}, \sigma_{j}\right)$ are the end coordinates of the $j^{\text {th }}$ line segment; $(w(y), \sigma(y))$ is a point on the line segment; and $j$ $=1,2, \ldots i$. By assigning a certain trial value for $\sigma_{i}$ that satisfies Equation (2), and using Equation (3), all of the nodal stresses along the FPZ can be obtained.

(5) Inputting the nodal stress $\sigma(y)$ into the FEM and to compute the displacements at the collocation points

The nodal cohesive stress $\sigma_{i}$ is accepted only when two additional requirements, displacement and stress, are satisfied as follows.

The displacement requirement is

$$
\left|d_{n}-d_{e}\right|<\text { Tolerance }
$$

where $d_{n}$ and $d_{e}$ represent the calculated and measured displacements, respectively, in terms of $\delta$, CMOD and NTOD (Fig. 2b).

For the stress requirement, the calculated stresses in the relevant domain should not be greater than $f_{t}$, and the numerical stress profile in the FPZ should be a smooth curve. Prior to the formation of a fully developed FPZ, all nodal cohesive stresses should be greater than zero.

(6) Proceeding to the next loading step and repeating procedures (3) to (5) until the crack opening at the initial notch tip reaches $w_{c}$ and $\sigma_{i}=0$.

\section{Experimental works and results}

\subsection{Mix proportions and specimen dimensions}

Five batches of concrete samples with compressive strengths varying from $40 \mathrm{MPa}$ to

$90 \mathrm{MPa}$ were cast. The mix proportions of concrete are shown in Table 1. Portland 
Cement CEM I 52.5N [34] was used. The maximum size of the aggregate was $10 \mathrm{~mm}$. For each batch, 4-5 pre-notched beams were prepared for three-point bending tests. The beam dimension was $710 \times 150 \times 80 \mathrm{~mm}$. The span of the beam was $600 \mathrm{~mm}$. The prenotch depth was $45 \mathrm{~mm}$, and the thickness of the notch was $3 \mathrm{~mm}$.

In addition to the pre-notched beams, three cubes were cast with each batch. The dimension of each cube was $150 \times 150 \times 150 \mathrm{~mm}$. After being cast and cured, the specimens were placed in air (temperature: $20 \pm 2{ }^{\circ} \mathrm{C}$; relative humidity: 75 - 85\%) until the date of testing. The pre-notched beams were cast for three-point bending tests according to RILEM recommendations [35, 36]. Following the Hong Kong Construction Standard [37], the cubes were tested to determine the cube compressive strength $f_{c u}$.

To eliminate the variation of the material properties due to the differences in the samples, cylinders were cored from the fractured segments of the pre-notched beams after conducting the three-point bending test. The cylinder specimen had a dimension of $100 \times 80 \mathrm{~mm}$ in diameter and depth, respectively. The cylinder specimens were tested using the splitting tension test [38] to determine the indirect tensile strength, $f_{t}$. The material properties of concrete with different strengths are listed in Table 1.

\subsection{Experimental setup of three-point bending test}

Using an MTS and bend fixture, three-point bending tests were carried out on the 28th day after casting the specimens. The experimental setup is presented in Fig. 4a. Displacement control with a loading rate of $0.01 \mathrm{~mm} / \mathrm{min}$ of the jack displacement was used, and the jack was moved upward to apply load on the beam. The mid-span deflection and crack mouth opening displacement (CMOD) were measured by LVDTs and a clip gauge, respectively. By using a very stiff servo-controlled testing machine, 
the growth of the main crack was well controlled, and the complete load-deflection and load-CMOD curves were recorded by a data logger. Schema of the experimental setup is shown in Fig. 4b. To measure the mid-span deflection without support disturbances, an additional frame was located on the top of the beam to act as a reference datum of LVDTs (see Fig. 4c).

A 3D ESPI system (Q300 produced by Dantec-Ettemeyer) was used to measure the surface deformation at the mid-span of the beams. In this study, the measured area was approximately 200 (horizontal) $\times 170$ (vertical) $\mathrm{mm}^{2}$. The measurement sensitivity of the ESPI system depends on the illumination arm, object distance and laser wavelength. With a longer illumination arm, shorter object distance and laser wavelength, the measurement sensitivity will be higher. With the present test setup, the system is capable of obtaining a displacement resolution of $0.2 \mu \mathrm{m}$.

At each loading state, the speckle pattern on the measured surface was captured by the ESPI sensor. The post-processing software ISTRA [39] was used to convert ESPI raw data to in-plane displacement distributions.

\subsection{Observations of rupture planes}

The rupture planes of the specimens with various strengths are shown in Fig. 5. In the planes of rupture, it can be observed that cement and aggregate exhibit different colours. For normal-strength concrete (NSC), few aggregates are broken, and the crack propagates through the cement matrix or along the transition zone of the cement and aggregate. The plane of rupture shows a uniform colour, termed as an intergranular fracture mode. For high-strength concrete (HSC) ( $f_{c u} \geq 60 \mathrm{MPa}$ ), the crack continues through the aggregate and is termed as a transgranular fracture mode. With more 
aggregate surface, the colour of the rupture plane seems diverse and non-uniform. The higher the compressive strength is, the more the aggregate fractures.

It can be deduced that the crack initiates from the weaker zone. For NSC, the cement matrix has a lower strength relative to the strength of the aggregates, so the crack mainly occurs in the cement matrix or in the transition zone between the cement and the aggregates. For HSC, the strength of the cement matrix is comparable to or even higher than that of the aggregates; therefore, the crack propagates through the aggregates. The results are consistent with the findings by Elices et al. [18], who indicated that the dominant fracture mode was intergranular for concrete with weak interfaces whereas the dominant mode was transgranular for concrete with strong interfaces.

\subsection{Experimental load-displacement curves}

Complete load-deflection and load-CMOD curves of the pre-notched beams are presented in Fig. 6, including the specimen groups C40, C50, C60, C80 and C90. Due to the heterogeneity of concrete and the diversity of individual specimens, the loaddisplacement curves of the specimens in the same group might be different. To show the representative results, only the results of three specimens with consistent responses are presented for each group.

From the curves, it can be seen that at the early loading stages, e.g., $P / P_{\max }<1 / 3$, the specimens are nearly in linear elastic deformation. Nonlinear deformation is not observable in the initial segment of curves. The end of this segment is considered to be the initiation of fracture [40]. The load-deformation relationship in the linear segment will be used to estimate the Young's modulus of concrete in further numerical analysis. 
The average fracture energy $G_{F}$ can be obtained by the work-of-fracture method according to RILEM TC 50-FMC [35]. It is calculated from the entire load-deflection curve by

$$
G_{F}=\frac{A_{0}}{\left(b-a_{0}\right) t}
$$

where $A_{0}$ is the area under the measured load-deflection curve, $b$ and $t$ are the depth and thickness of the beam, respectively, and $a_{0}$ is the initial notch depth. The fracture energy values of the various specimen groups are shown in Table 2 .

\subsection{Observations of the crack evolution}

The high-precision ESPI camera allowed a vivid observation of the crack propagation in concrete. Fig. 7 shows a typical crack path in the pre-notched concrete beam (C90-1). With a pre-notched beam, the main crack propagated from the initial notch tip. Due to the heterogeneity of concrete, microcracks and bifurcations occurred along the growth path of the main crack. As shown in the figure, $x$ and $y$ represent the coordinates in the horizontal and vertical directions, respectively. The origin of the coordinates is at the centre of the notch mouth. The initial notch tip was at $x_{0}=0$ and $y_{0}=45 \mathrm{~mm}$.

To produce the crack evolution in the specimen, four critical loading stages were taken into account, as described in Fig. 8. Fringe maps of the measured surface at the four loading stages are shown in Fig. 9. The fringes represent contours of the displacement in the $x$ direction. All the points on one fringe have the same displacement and the difference in displacements between two adjacent fringes is about $2 \mu \mathrm{m}$. The fringe patterns reveal the details of crack evolution in the FPZ. A crack can be identified from the discontinuity of the fringes, while the crack tip is recognised as the region with a rapid change of fringes. 
As shown in Fig. 9, at the critical loading stage (1), the crack initiates and bifurcates from the initial notch tip. The bifurcations of the crack are also named as secondary cracks. The orientations of the secondary cracks relative to the sides of the notch tip are nearly symmetric to and at approximately $40^{\circ}$ to the notch plane. It can be deduced that the maximum principal stress close to the crack tip is not similar to that of the main crack, which can be interpreted by the influence of the T-stress. It has been shown that when T-stress in front of a Mode I crack is positive, the straight crack path is unstable and deviates from its original growth direction [41]. Similar phenomena were observed by Guinea et al. [42]. They suggested that the maximum principal stress close to the crack tip was parallel to the crack rather than normal to it and that the secondary cracks should develop approximately normal to the main crack. Both Guinea's results and the present results indicate that the secondary cracks opened a small amount to relax the local stress and then closed again as the main crack propagated.

Although secondary cracks are observable in the test and secondary diffuse cracking is required in the theoretical model, the effect of secondary cracking on the overall response of the specimen is small (on the order of a few percent in the load-deflection curve) [43].

The FPZ is a damage zone in which fracture toughening mechanisms, such as microcracking, crack deflection, aggregate bridging, crack branching, etc., exist and the energy is dissipated. The width of FPZ is the thickness of the damage zone containing all the aforementioned cracking activities, thus the width of the FPZ can be determined from the region containing all the cracks, i.e. discontinuities of fringe patterns. The size of the FPZ is believed to depend on the resolution of the visualisation method [44]. From the fringe maps at the critical loading stages (1) to (3), it can be seen that the width of the FPZ is approximately $33 \mathrm{~mm}$, which is 3.3 times the maximum aggregate 
size in these concrete samples. The experimental observation in this study is consistent with previous findings that the FPZ width is approximately $35 \mathrm{~mm}$ [6] and that the width of the crack band at the crack front equals approximately 3 times the maximum aggregate size [5, 45]. At the loading stage (4), the main crack propagates extensively and the uncracked ligament becomes very thin (approximately $10 \mathrm{~mm}$ ). The secondary cracks closed at this loading stage, and the width of the fracture process zone is approximately $10 \mathrm{~mm}$.

The width of the FPZ is important in determining the COD profile. To calculate the COD profile, relative horizontal displacements are required along two cross sections beside the crack. To take into account the effects of all mechanisms in the FPZ, the cross sections should be beyond the FPZ.

\subsection{COD profiles and crack lengths of C90-1}

The COD profiles at the four loading stages are analysed and presented in Fig. 10.

From the experimental curves, it can be observed that the COD profile does not vary linearly as previously assumed [1]. Hence, nonlinear assumptions are more appropriate for modelling the COD profile, especially in the FPZ. It can provide a reference for the calculations referring to the crack opening.

From the COD profiles, the crack length can be determined. The crack front is identified at the position where the crack opening $w$ reduces to zero. Due to fluctuations in the experimental data and the measurement precision of ESPI sensor, $w<2 \mu \mathrm{m}$ is used for the identification of the location of the cohesive crack front. The initial notch tip $y_{0}=$ $45 \mathrm{~mm}$ ) is regarded as the rear end of the cohesive crack.

As shown in Fig. 10, at the pre-peak load level of $60 \%$ of the peak load, the crack opening at the initial notch tip, which is termed NTOD, is approximately $6 \mu \mathrm{m}$. The 
crack length is approximately $7 \mathrm{~mm}$. At the peak load, the NTOD is approximately 30 $\mu \mathrm{m}$ with a crack length of approximately $44 \mathrm{~mm}$. At the post-peak load level of $60 \%$ of the peak load, the NTOD is approximately $100 \mu \mathrm{m}$, and the crack length is approximately $75 \mathrm{~mm}$. At the post-peak load level of 30\% of the peak load, the NTOD reaches approximately $185 \mu \mathrm{m}$, and the crack length reaches approximately $89 \mathrm{~mm}$.

When an FPZ is fully developed, the crack opening for a cohesive crack and length of the FPZ reach the maximum values. Because the crack rear end will move forward as well, it is difficult to determine the state of a fully-developed TSC based only on the experimental results.

\section{Numerical simulation and results}

\subsection{Description of the numerical model}

The three-point bending test was simulated using the FEM. Due to the symmetry of the specimen, only half of the beam was analysed. The specimen configuration and finite element meshes are illustrated in Fig. 11. A total of 450 9-node hybrid elements [46] were used in the analysis. The bulk material was assumed to behave in a linear elastic manner. Poisson's ratio of plain concrete was shown to vary within $0.15-0.25$. Because Poisson's ratio had little influence on the numerical response in the finite element analysis, a Poisson's ratio of 0.2 was assumed for the concrete in this study.

As an example, Specimen C90-1 was utilized during the pre-peak load at $94 \%$ of the peak load (Fig. 11). The beam section along the crack can be divided into three zones: the real crack zone ( $y=0-45 \mathrm{~mm}$ ), the cohesive crack zone ( $y=45-75 \mathrm{~mm}$ ) and the linear elastic zone ( $y=75-150 \mathrm{~mm}$ ). The calculated cohesive stress $\sigma(y)$ was added to the cohesive zone to simulate the nonlinear fracture response of the beam. By 
minimising the discrepancy between the numerical displacements and the experimental displacements at the collocation points, the cohesive stress was determined.

\subsection{The TSCs of concrete}

The TSCs of concrete with compressive strength varying from $40 \mathrm{MPa}$ to $90 \mathrm{MPa}$ are presented in Fig. 12. The results of this study were compared with the bilinear CEB-FIP model [47]. From the figures, it can be observed that the initial segments of the TSCs are consistent with the model of CEB-FIP. For normal strength concrete C40, the tails of the estimated TSCs are much shorter than those of the CEB-FIP model. For high strength concrete C90 (e.g. C90), the estimated TSC is close to the CEB-FIP model.

The parameters used to describe the TSCs are tabulated in Table 2. As the compressive strength increases, the Young's modulus $E$ estimated by the IDCM has an increasing trend, with one exception: C60 concrete has a slightly lower E value than C50. The tensile strength $f_{t}$ increases with the increase of compressive strengths, showing the same trend as the computational results found by Slowik et al. [48]. However, the characteristic crack opening $w_{c}$ does not show an increasing trend, and C60 concrete has a maximum $w_{c}$ of approximately $240 \mu \mathrm{m}$. Previous studies [29, 49-51] have indicated that the $w_{c}$ of different types of concrete varied within 120-350 $\mu \mathrm{m}$, which agrees with the present results.

The estimated TSCs of all concrete strengths are presented in Fig. 13. The results of the present study were compared with the TSC obtained by Kitsutaka [50] using polylinear approximation analysis. Our results were also compared with the results of de Oliveira e Sousa and Gettu [49] using inverse analysis on the assumption that the shape of the TSC was sloped-constant and bilinear. From these comparisons, it can be shown that the 
present results provide reasonable estimations for concrete TSCs. TSCs obtained using different methods are quite consistent in the middle part of the TSC; the main differences lie in the tensile strength and in the tail of the TSC.

To compare the shapes of the estimated TSCs of various concrete strengths, graphs of normalised stress $\sigma / f_{t}$ versus normalised crack opening $w / w_{c}$ are presented in Fig. 14. By comparison, good agreement was observed between the present results and the exponential curve proposed by Cornelissen et al. [52].

\subsection{Verifications of the estimated TSCs}

Previous studies [29, 41, 42] indicate that the specific fracture energy of concrete can be used as a size-independent material property if the span-to-depth ratio and notch-todepth ratio of the beam are certain. In addition, the fracture energy can be obtained from a fully developed tension softening curve. With a fully developed TSC, the fracture energy can be derived from the integral

$$
G_{F}^{T S C}=\int_{0}^{w_{c}} \sigma d w
$$

By comparing the fracture energies obtained from TSC and the load-displacement curve, the accuracy of the tension softening curve can be verified.

The fracture energies determined from the $P$ - $\delta$ curve and the TSC are shown in Table 2. With differences of less than $10 \%$, a satisfactory agreement can be observed between the two energies. Generally, the fracture energies calculated from the $P$ - $\delta$ curve are higher than those derived from the TSC, which can be explained by the different mechanisms of energy consumption. The fracture energy derived from the $P$ - $\delta$ curve is based on the assumption that energy absorption takes place only in the FPZ, and all the deformations outside the FPZ are purely elastic [1]. However, a small proportion of the 
energy might be consumed by friction and the formation of microcracks outside the FPZ; thus, the fracture energy could be overestimated when it is derived from the $P$ - $\delta$ curve.

Taking C90-2 as an example, the displacements of the beam at various loading steps were calculated using the material properties obtained from C90-1 to validate the present results. As shown in Fig. 15, excellent agreement is observed between the numerical load-displacement curves and the experimental load-displacement curves over the entire loading process. The results demonstrate that the global responses of the beam specimens are not sensitive to small variations in fracture and material properties of concrete.

\subsection{Parametric analysis of the TSCs}

To facilitate future simulations of concrete fractures using commercial finite element packages, the TSCs identified in the current study were simplified to bilinear [53] and exponential [54] curves using regression analysis, as shown in Fig. 16. The basic parameters used to define the TSC, including the total fracture energy $G_{F}$ and the critical crack opening displacement $w_{c}$, were obtained using inverse analysis. The tensile strength was obtained from the splitting tension test. In addition to these parameters, parameters are determined for each individual curve.

(1) Bilinear curve

As shown in Fig. 16a, the critical parameter for a bilinear curve is the location of the kink point $\left(w_{1}, f_{1}\right)$.

(2) Exponential curve

As shown in Fig. 16b, the exponential curve was derived empirically by Hordijk [54]. The function is expressed as 


$$
\begin{gathered}
\frac{\sigma}{f_{t}}=\left\{1+\left(c_{1} \frac{w}{w_{c}}\right)^{3}\right\} \exp \left(-c_{2} \frac{w}{w_{c}}\right)-\frac{w}{w_{c}}\left(1+c_{1}^{3}\right) \exp \left(-c_{2}\right) \\
w_{c}=c_{3} \frac{G_{F}}{f_{t}}
\end{gathered}
$$

where $c_{1}, c_{2}$ and $c_{3}$ are the parameters of the exponential curves to be determined for concrete.

A complete set of parameters for defining the bilinear and exponential curves are listed in Table 3. To compare the modelling effect of the idealised curves, the root-meansquare deviation (RMSD) was evaluated, as presented in Table 3. For concrete with compressive strength $f_{c u} \leq 60 \mathrm{MPa}$, the bilinear curve can model the TSCs fairly accurately, while for C80 and C90 concrete, the RMSD of bilinear fitting is statistically significant. For bilinear fitting, the stress ratio $f_{1} / f_{t}$ at the kink point varies within 0.21 0.28. Exponential curves can provide satisfactory approximations for the TSCs of all concrete strengths.

To ease the estimation of the fracture properties of concrete, the parameters for defining an exponential TSC were related to the compressive strength $f_{c u}$, as shown in Fig. 17. Empirical equations for $c_{1}, c_{2}$ and $c_{3}$ were expressed in terms of $f_{c u}$ that ranges from 40 MPa to $90 \mathrm{MPa}$.

$$
\begin{aligned}
& c_{1}=2.965 \exp \left(0.0165 f_{c u}\right) \\
& c_{2}=0.431 \exp \left(0.0304 f_{c u}\right) \\
& c_{3}=4.486 \exp \left(0.0053 f_{c u}\right)
\end{aligned}
$$

From the empirical formulas, the parameters of the exponential TSC seem only rely on the compressive strength. However, it should be noted that the tensile properties of concrete are dependent on the physical properties of the material, e.g. aggregate size, 
and the size of the tested specimen. With comparable aggregate size and specimen size, current empirical formulas are feasible to estimate the TSC from the compressive strength even for concrete with compressive strengths outside the range of 40-90 MPa.

\subsection{The crack length and length of the FPZ}

The cohesive stress distribution of the FPZ depends on the length of the FPZ, so the length is an important factor in the CCM [55]. Due to the rarity of experimental data on the FPZ and the crack length, the establishment of the effective fracture mechanics parameter for concrete is hindered [16]. The present study allows an estimation of the length of the FPZ based on both experimental observations and numerical analyses.

From the COD profiles, the crack front $y_{t}$ was identified at the position where the crack opening $w$ was reduced to zero. The initial notch tip $\left(y_{0}=45 \mathrm{~mm}\right)$ was considered the end of the cohesive crack. The length of the FPZ, $l_{F P Z}$, was determined by

$$
l_{F P Z}=y_{t}-y_{0}
$$

When a fully developed FPZ was formed, the end of the crack would move forward from the initial notch tip at $y_{0}=45 \mathrm{~mm}$; thus, it was necessary to identify the new end of the crack to estimate the length of the FPZ.

The relationships between the applied load and the length of the FPZ were analysed for various specimen groups. To compare the applied loads on specimens with different compressive strengths, the normalised load $P / P \max$ was used. $P / P \max$ versus $l_{F P Z}$ curves are shown in Fig. 18. It can be seen that the curves of the specimens with different concrete strengths have similar shapes. As shown in the figure, the curves can generally be divided into three phases. 
(1) In phase I, $P / P \max \leq 0.3, l_{F P Z}$ was relatively small, indicating that the crack tip had propagated slightly and that the beam was approximately in a linear deformation stage. These results coincide with most findings in the literature, which found that the concrete material is in elastic deformation when the load is smaller than one third of the peak load.

(2) In phase II, $l_{F P Z}$ propagated quickly. At the peak load, $l_{F P Z}$ was approximately 38-42 mm. In relation to the propagation of the FPZ, the load decreased gradually.

(3) In phase III, when the FPZ was fully developed, the load dropped to approximately 0.3 of the peak load. The crack opening was more apparent than the propagation of the crack, so the length of the FPZ decreased. A similar phenomenon was observed by Zhang and $\mathrm{Wu}$ [3], who indicated that the saturated FPZ moved ahead and shrank as the crack extended; thus, the length of the FPZ decreased after saturation. The maximum length of the fully developed FPZ was approximately $90 \mathrm{~mm}$, which is in excellent agreement with the results of Hadjab et al., who used acoustic emission [6] and scanning electron microscopy [56]. However, the length of the FPZ may be dependent on size and geometry [3] and may also be influenced by aggregate characteristics [15].

\section{Conclusions}

In this study, fracturing phenomena of concrete specimens under three-point bend were examined using the ESPI technique. The experimental results were presented. The TSCs of plain concrete with compressive strengths varying from $40 \mathrm{MPa}$ to $90 \mathrm{MPa}$ were determined using the IDCM. The following conclusions can be drawn:

(1) The fracture modes for NSC and HSC were different. In NSC, the crack mainly propagated across the cement matrix or along the interface between the cement and aggregates; thus, the dominant fracture mode was intergranular. In HSC, the strength of 
the cement paste was comparable to or even higher than that of the aggregates; thus, the crack propagated through the aggregates, and the dominant fracture mode was transgranular.

(2) In crack evolution, microcracks and crack bifurcations were observed. Due to the influence of the T-stress, the material close to the crack tip was in a bi-axial stress state and secondary crack occurred. The secondary crack was found to have an angle of $40^{\circ}$ to the notch plane. The width of the fracture process zone was approximately $33 \mathrm{~mm}$, while the crack length reached approximately $90 \mathrm{~mm}$.

(3) By analysing the crack length in concrete at different loading states, the fracture mechanism of the FPZ was analysed. There were three phases: in phase I, the specimen was in linear elastic deformation and fracture toughening was slight; in phase II, fracture mechanisms were mainly in the forms of microcracks and bifurcations; in phase III, only the main crack consumed the energy; thus, the bridging mechanism was dominant. At the peak load, the crack length was approximately $40 \mathrm{~mm}$. The maximum length of the FPZ was found to be approximately $90 \mathrm{~mm}$.

(4) The characteristic crack opening $w_{c}$ for various concrete strengths varied within 165$240 \mu \mathrm{m}$. C60 concrete had the maximum $w_{c}$ of approximately $240 \mu \mathrm{m}$.

(5) By approximating the estimated TSCs as bilinear and exponential curves, it is found that the bilinear curve can accurately model the TSCs of only normal strength concrete, while the exponential curve is appropriate to model the TSCs of all concrete strengths. 


\section{References}

[1] Shah SP, Swartz SE, Ouyang C. Fracture Mechanics of Concrete: Applications of Fracture Mechanics to Concrete, Rock and Other Quasi-Brittle Materials. New York: John Wiley \& Sons, Inc.; 1995.

[2] Wecharatana M, Shah SP. Predictions of Nonlinear Fracture Process Zone in Concrete - Closure. J Eng Mech-Asce 1985;111(1):115-7.

[3] Zhang D, Wu K. Fracture process zone of notched three-point-bending concrete beams. Cem Concr Res 1999;29(12):1887-92.

[4] Slowik M. Numerical analysis of the width of fracture process zone in concrete beams. Comp Mater Sci 2011;50(4):1347-52.

[5] Denarie E, Saouma VE, Iocco A, Varelas D. Concrete fracture process zone characterization with fiber optics. J Eng Mech-Asce 2001;127(5):494-502.

[6] Hadjab H, J.-Fr.Thimus, Chabaat M. Fracture process zone in notched concrete beams treated by using acoustic emission. NDT.net 2004;12(12).

[7] Jankowski LJ, Stys DJ. Formation of the Fracture Process Zone in Concrete. Eng Fract Mech 1990;36(2):245-53.

[8] Maji A, Shah SP. Process Zone and Acoustic-Emission Measurements in Concrete. Exp Mech 1988;28(1):27-33.

[9] Otsuka K, Date H. Fracture process zone in concrete tension specimen. Eng Fract Mech 2000;65(2-3):111-31.

[10] $\mathrm{Hu} \mathrm{XZ}$, Duan K. Influence of fracture process zone height on fracture energy of concrete. Cem Concr Res 2004;34(8):1321-30.

[11] Horii H, Ichinomiya T. Observation of Fracture Process Zone by Laser Speckle Technique and Governing Mechanism in Fracture of Concrete. Int J Fracture 1991;51(1):19-29. 
[12] Muralidhara S, Prasad BKR, Eskandari H, Karihaloo BL. Fracture process zone size and true fracture energy of concrete using acoustic emission. Constr Build Mater 2010;24(4):479-86.

[13] Du JJ, Kobayashi AS, Hawkins NM. An Experimental-Numerical Analysis of Fracture Process Zone in Concrete Fracture Specimens. Eng Fract Mech 1990;35(13):15-27.

[14] Yu RC, Zhang XX, Ruiz G, Tarifa M, Camara M. Size of the fracture process zone in high-strength concrete at a wide range of loading rates. Appl Mech Mater 2010;2425:155-60.

[15] He S, Feng Z, Rowlands RE. Fracture process zone analysis of concrete using moire interferometry. Exp Mech 1997;37(3):367-73.

[16] Kitsutaka Y. Fracture parameters by polylinear tension-softening analysis. J Eng Mech-Asce 1997;123(5):444-50.

[17] Muralidhara S, Prasad BKR, Karihaloo BL, Singh RK. Size-independent fracture energy in plain concrete beams using tri-linear model. Constr Build Mater 2011;25(7):3051-8.

[18] Elices M, Rocco C, Rosello C. Cohesive crack modelling of a simple concrete: Experimental and numerical results. Eng Fract Mech 2009;76(10):1398-410.

[19] Hu X. Size effect on tensile softening relation. Mater Struct 2011;44(1):129-38.

[20] Alterman D, Akita H. Prediction of Tension Softening Curve in Concrete Using Artificial Neural Networks. Advanced Materials Research 2008;41 - 42:277-82.

[21] Gopalaratnam VS, Shah SP. Softening Response of Plain Concrete in Direct Tension. ACI Journal 1985;82(3):310-23.

[22] Boone TJ, Wawrzynek PA, Ingraffea AR, Gopalaratnam VS, Shah SP. Softening Response of Plain Concrete in Direct Tension. ACI Journal 1986;83(2):316-8. 
[23] Lee SK, Woo SK, Song YC. Softening response properties of plain concrete by large-scale direct tension tests. Mag Concrete Res 2008;60(1):33-40.

[24] Elices M, Guinea GV, Gomez J, Planas J. The cohesive zone model: advantages, limitations and challenges. Eng Fract Mech 2002;69(2):137-63.

[25] Wittmann FH, Rokugo K, Brühwiler E, Mihashi H, Simonin P. Fracture energy and strain softening of concrete as determined by means of compact tension specimens. Mater Struct 1988;21(1):21-32.

[26] De Oliveira JLA, Gettu R. Determining the tensile stress-crack opening curve of concrete by inverse analysis. J Eng Mech-Asce 2006;132(2):141-8.

[27] Hillerborg A, Modéer M, Petersson PE. Analysis of Crack Formation and Crack Growth in Concrete by Means of Fracture Mechanics and Finite Elements. Cem Concr Res 1976;6(6):773-82.

[28] Guinea GV, Planas J, Elices M. A General Bilinear Fit for the Softening Curve of Concrete. Mater Struct 1994;27(166):99-105.

[29] Abdalla HM, Karihaloo BL. A method for constructing the bilinear tension softening diagram of concrete corresponding to its true fracture energy. Mag Concrete Res 2004;56(10):597-604.

[30] Kitsutaka Y. Fracture Parameters for Concrete Based on Poly-Linear Approximation Analysis of Tension Softening Diagram. In: Fracture Mechanics of Concrete Structures, Proceedings FRAMCOS-2 (edited by Wittmann FH) 1995:199-208. [31] Rokugo K, Uchida Y, Koyanagi W. Determination of Tension Softening Diagrams of Concrete by Means of Bend Tests on Notched Beams and Applications. In: Numerical Models in Fracture Mechanics of Concrete (edited by Wittmann FH) 1993:67-81. 
[32] Bazant ZP. Concrete fracture models: testing and practice. Eng Fract Mech 2002;69(2):165-205.

[33] Su RKL, Chen HHN, Kwan AKH. Incremental displacement collocation method for the evaluation of tension softening curve of mortar. Eng Fract Mech 2012;88:49-62. [34] BS EN 197-1:2000. Cement-Part 1: Composition, specifications and conformity criteria for common cements. In: BSI, editor.2007.

[35] RILEM. TC 50-FMC Fracture Mechanics of Concrete, Determination of the Fracture Energy of Mortar and Concrete by Means of Three-point Bend Tests on Notched Beams. Mater Struct 1985;18(4):287-90.

[36] RILEM. TC89-FMT Fracture Mechanics of Concrete Test Methods, Determination of Fracture Parameters (KIcs and CTODc) of Plain Concrete Using Three-point Bend Tests. Mater Struct 1990;23(6):457-60.

[37] Government of Hong Kong. Construction Standard: Testing Concrete: Volume 2. Hong Kong 1990.

[38] ASTM C 496. Standard Test Method for Splitting Tensile Strength of Cylindrical Concrete Specimens. 1996.

[39] Dantec-Ettemeyer. ISTRA for Windows, Version 3.3.12. 2001.

[40] Xu SL, Zhang XF. Determination of fracture parameters for crack propagation in concrete using an energy approach. Eng Fract Mech 2008;75(15):4292-308.

[41] Cotterell B, Rice JR. Slightly Curved or Kinked Cracks. Int J Fracture 1980;16(2):155-69.

[42] Planas J, Elices M, Guinea GV. Measurement of the fracture energy using threepoint bend tests: Part 2-Influence of bulk energy dissipation. Mater Struct 1992;25(5):305-12. 
[43] Planas J, Elices M, Guinea GV, Gomez FJ, Cendon DA, Arbilla I. Generalizations and specializations of cohesive crack models. Eng Fract Mech 2003;70(14):1759-76.

[44] J. G. M. van Mier, H. K. Man. Some notes on microcracking, softening, localization, and size effects. Int J Damage Mech 2009;18(3):283-309.

[45] Bazant ZP. Size Effect in Blunt Fracture - Concrete, Rock, Metal. J Eng MechAsce. 1984;110(4):518-35.

[46] Sze KY, Fan H, Chow CL. Elimination of Spurious Pressure and Kinematic Modes in Biquadratic 9-Node Plane Element. Int J Numer Meth Eng 1995;38(23):3911-32.

[47] CEB-90. CEB-FIP mode code 1990. Committee Euro-International du Beton. 1991. [48] Slowik V, Villmann B, Bretschneider N, Villmann T. Computational aspects of inverse analyses for determining softening curves of concrete. Comput Method Appl M 2006;195(52):7223-36.

[49] de Oliveira e Sousa J, Gettu R. Determining the Tensile Stress-Crack Opening Curve of Concrete by Inverse Analysis. Journal of Engineering Mechanics 2006;132(2):141-8.

[50] Kitsutaka Y. Fracture Parameters by Polylinear Tension-Softening Analysis. Journal of Engineering Mechanics 1997;123(5):444-50.

[51] Li VC, Chan CM, Leung CKY. Experimental-Determination of the TensionSoftening Relations for Cementitious Composites. Cem Concr Res 1987;17(3):441-52. [52] Cornelissen HAW, Hordijk DA, Reinhardt HW. Experimental determination of crack softening characteristics of normalweight and lightweight concrete. HERON $1986 ; 31(2)$.

[53] Roelfstra PE, Wittmann FH. Numercial method to link strain softening with failure of concrete. In: Fracture Toughness and Fracture Energy of Concrete (edited by FH Wittmann) 1986:163-75. 
[54] Hordijk DA. Local approach to fatigue of concrete, PhD dissertation. 1991(Delft University of Technology).

[55] Wang LM, Xu SL, Zhao XQ. Analysis on cohesive crack opening displacement considering the strain softening effect. Sci China Ser G 2006;49(1):88-101.

[56] Hadjab-Souag H, Thimus JF, Chabaat M. Detecting the fracture process zone in concrete using scanning electron microscopy and numerical modelling using the nonlocal isotropic damage model. Can J Civil Eng 2007;34(4):496-504. 
Table 1 Mix proportions and mechanical properties of concrete.

\begin{tabular}{ccccccccc}
\hline Series & $\begin{array}{c}\text { Water } \\
\left(\mathrm{kg} / \mathrm{m}^{3}\right)\end{array}$ & $\begin{array}{c}\text { Cement } \\
\left(\mathrm{kg} / \mathrm{m}^{3}\right)\end{array}$ & $w / c$ & $\begin{array}{c}\text { Fine } \\
\text { aggregate } \\
\left(\mathrm{kg} / \mathrm{m}^{3}\right)\end{array}$ & $\begin{array}{c}\text { Coarse } \\
\text { aggregate } \\
\left(\mathrm{kg} / \mathrm{m}^{3}\right)\end{array}$ & $\begin{array}{c}\text { Super } \\
\text { plasticiser } \\
\left(\mathrm{g} / \mathrm{m}^{3}\right)\end{array}$ & $f_{c u}(\mathrm{MPa})$ & $f_{t}(\mathrm{MPa})$ \\
\hline C40 & 200 & 279 & 0.72 & 1025 & 838 & 0 & 39.7 & 2.5 \\
C50 & 193 & 332 & 0.58 & 905 & 905 & 432 & 49.1 & 2.9 \\
C60 & 196 & 423 & 0.46 & 867 & 866 & 3802 & 62.2 & 3.3 \\
C80 & 173 & 482 & 0.36 & 867 & 866 & 6263 & 80.5 & 4.5 \\
C90 & 160 & 501 & 0.32 & 867 & 866 & 8516 & 86.7 & 5.4 \\
\hline
\end{tabular}

Table 2 Experimental and numerical results.

\begin{tabular}{|c|c|c|c|c|c|c|c|c|c|}
\hline Series & $\begin{array}{c}\text { Number } \\
\text { of } \\
\text { samples }\end{array}$ & $\begin{array}{c}\delta_{c} \\
(\mathrm{~mm})\end{array}$ & $\begin{array}{c}P_{c} \\
(\mathrm{~N})\end{array}$ & $\begin{array}{l}\text { CMOD } \\
{ }_{c}(\mathrm{~mm})\end{array}$ & $\begin{array}{c}\mathrm{NTOD}_{c} \\
(\mathrm{~mm})\end{array}$ & $\begin{array}{l}G_{F}^{P-\delta} \\
(\mathrm{N} / \mathrm{m})\end{array}$ & $\begin{array}{l}G_{F}^{T S C} \\
(\mathrm{~N} / \mathrm{m})\end{array}$ & $\begin{array}{c}w_{c} \\
(\mu \mathrm{m})\end{array}$ & $\begin{array}{c}E \\
(\mathrm{GPa})\end{array}$ \\
\hline \multirow{5}{*}{ C40 } & C40-1 & 0.077 & 2805 & 0.051 & 0.025 & 95 & 94.9 & 220 & 21 \\
\hline & C40-2 & 0.088 & 2920 & 0.058 & 0.026 & 95.8 & 92.3 & 192 & 21 \\
\hline & C40-3 & 0.089 & 3048 & 0.062 & 0.025 & 104.5 & 102 & 230 & 21.5 \\
\hline & Mean & 0.085 & 2924 & 0.057 & 0.025 & 98.4 & 96.4 & 214.0 & 21.2 \\
\hline & Std dev. & 0.007 & 122 & 0.006 & 0.001 & 5.3 & 5.0 & 19.7 & 0.3 \\
\hline \multirow{5}{*}{ C50 } & C50-1 & 0.096 & 3763 & 0.058 & 0.021 & 123.6 & 118.8 & 178 & 23.5 \\
\hline & C50-2 & 0.090 & 3793 & 0.067 & 0.027 & 122.4 & 122.2 & 185 & 24 \\
\hline & C50-3 & 0.093 & 3908 & 0.068 & 0.026 & 128.7 & 119.3 & 190 & 24 \\
\hline & Mean & 0.093 & 3821 & 0.064 & 0.025 & 124.9 & 120.1 & 184.3 & 23.8 \\
\hline & Std dev. & 0.003 & 77 & 0.006 & 0.003 & 3.3 & 1.8 & 6.0 & 0.3 \\
\hline \multirow{5}{*}{ C60 } & C60-1 & 0.110 & 3994 & 0.068 & 0.031 & 141.9 & 128.1 & 251 & 22.5 \\
\hline & C60-2 & 0.114 & 3751 & 0.073 & 0.027 & 133.4 & 132.2 & 240 & 22 \\
\hline & C60-3 & 0.093 & 3998 & 0.061 & 0.032 & 130.3 & 128.6 & 224 & 24.5 \\
\hline & Mean & 0.106 & 3914 & 0.067 & 0.030 & 135.2 & 129.6 & 238.3 & 23.0 \\
\hline & Std dev. & 0.011 & 141 & 0.006 & 0.003 & 6.0 & 2.2 & 13.6 & 1.3 \\
\hline \multirow{5}{*}{ C80 } & C80-1 & 0.083 & 4481 & 0.056 & 0.018 & 133.4 & 133.2 & 186 & 28 \\
\hline & C80-2 & 0.097 & 3887 & 0.065 & 0.023 & 115.6 & 115.5 & 186 & 29 \\
\hline & C80-3 & 0.086 & 4553 & 0.052 & 0.025 & 124.3 & 123.8 & 194 & 30 \\
\hline & Mean & 0.089 & 4307 & 0.058 & 0.022 & 124.4 & 124.2 & 188.7 & 29.0 \\
\hline & Std dev. & 0.007 & 366 & 0.007 & 0.004 & 8.9 & 8.9 & 4.6 & 1.0 \\
\hline \multirow{5}{*}{ C90 } & C90-1 & 0.088 & 4230 & 0.058 & 0.026 & 108 & 107.8 & 166 & 30.5 \\
\hline & C90-2 & 0.088 & 4524 & 0.062 & 0.031 & 115.4 & 115.1 & 149 & 31 \\
\hline & C90-3 & 0.110 & 4016 & 0.072 & 0.031 & 121.1 & 120.8 & 180 & 28 \\
\hline & Mean & 0.095 & 4257 & 0.064 & 0.029 & 114.8 & 114.6 & 165.0 & 29.8 \\
\hline & Std dev. & 0.013 & 255 & 0.007 & 0.003 & 6.6 & 6.5 & 15.5 & 1.6 \\
\hline
\end{tabular}

Notes: $P_{c}, \delta_{c}, C M O D_{c}$ and $N T O D_{c}$ are the load, deflection, CMOD and NTOD at the peak, respectively. 
Table 3 Parameters of the idealised TSC curves.

\begin{tabular}{|c|c|c|c|c|c|c|c|c|c|c|c|c|}
\hline \multirow[b]{2}{*}{ Series } & \multicolumn{3}{|c|}{ Fracture parameters } & \multicolumn{5}{|c|}{ Bilinear curve } & \multicolumn{4}{|c|}{ Exponential curve } \\
\hline & $\begin{array}{c}G_{F} \\
(\mathrm{~N} / \mathrm{m})\end{array}$ & $\begin{array}{c}w_{c} \\
(\mu \mathrm{m})\end{array}$ & $\begin{array}{c}f_{t} \\
(\mathrm{MPa})\end{array}$ & $\begin{array}{c}w_{1} \\
(\mu \mathrm{m})\end{array}$ & $\begin{array}{c}f_{1} \\
(\mathrm{MPa})\end{array}$ & $w_{1} / w_{C}$ & $f_{1} / f_{t}$ & RMSD & $c_{1}$ & $c_{2}$ & $c_{3}$ & RMSD \\
\hline $\mathrm{C} 40$ & 96.4 & 214.0 & 2.5 & 22.9 & 0.7 & 0.11 & 0.28 & 0.075 & 1.5 & 6.0 & 5.6 & 0.201 \\
\hline $\mathrm{C} 50$ & 120.1 & 184.3 & 2.9 & 42.0 & 0.7 & 0.23 & 0.23 & 0.089 & 1.8 & 6.5 & 5.8 & 0.047 \\
\hline C60 & 129.6 & 238.3 & 3.3 & 33.0 & 0.7 & 0.14 & 0.21 & 0.137 & 2.9 & 7.9 & 6.1 & 0.108 \\
\hline C80 & 124.2 & 188.7 & 4.5 & 20.3 & 1.0 & 0.11 & 0.22 & 0.262 & 5.0 & 11 & 6.8 & 0.146 \\
\hline $\mathrm{C} 90$ & 114.6 & 165.0 & 5.4 & 12.0 & 1.2 & 0.07 & 0.22 & 0.258 & 6.0 & 13 & 7.2 & 0.187 \\
\hline
\end{tabular}

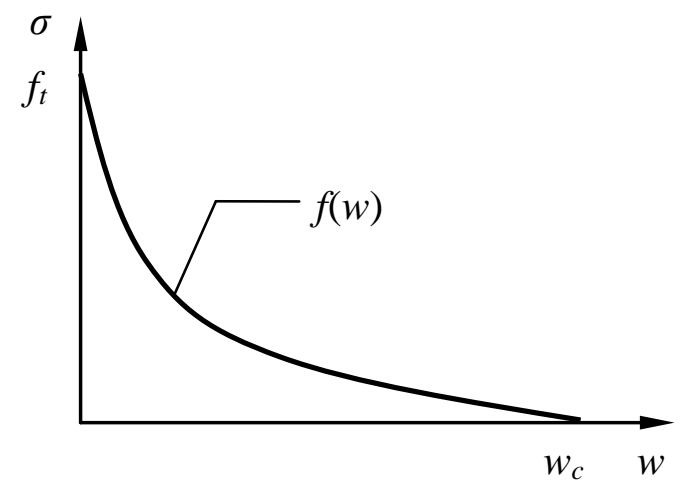

Fig. 1. A cohesive constitutive law.

(a)

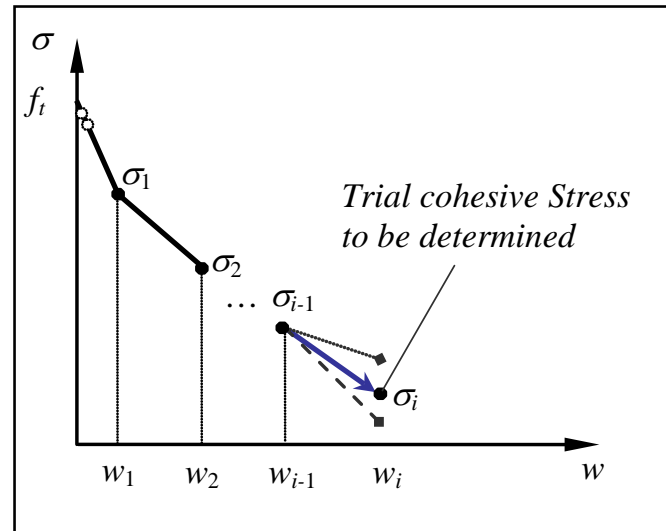

(b)

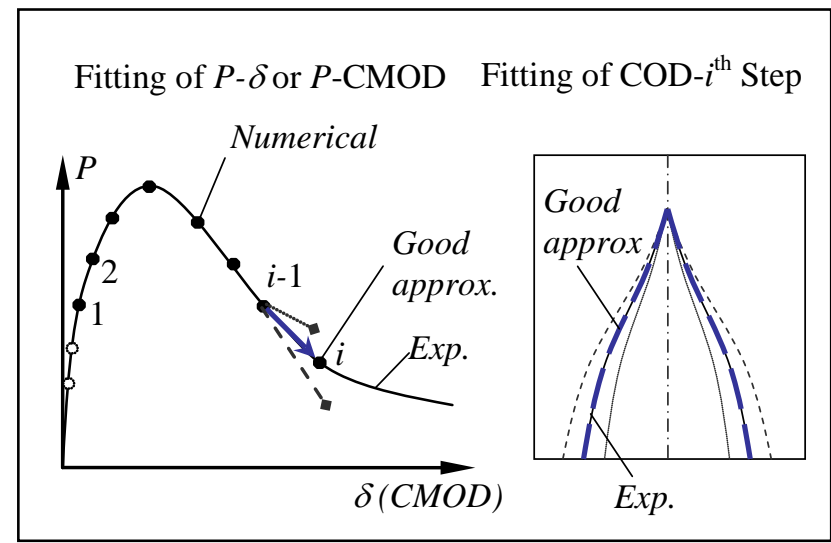

Fig. 2. The principle of the IDCM: (a) incremental construction of the TSC; (b) displacement collocation for trial stress estimations. 


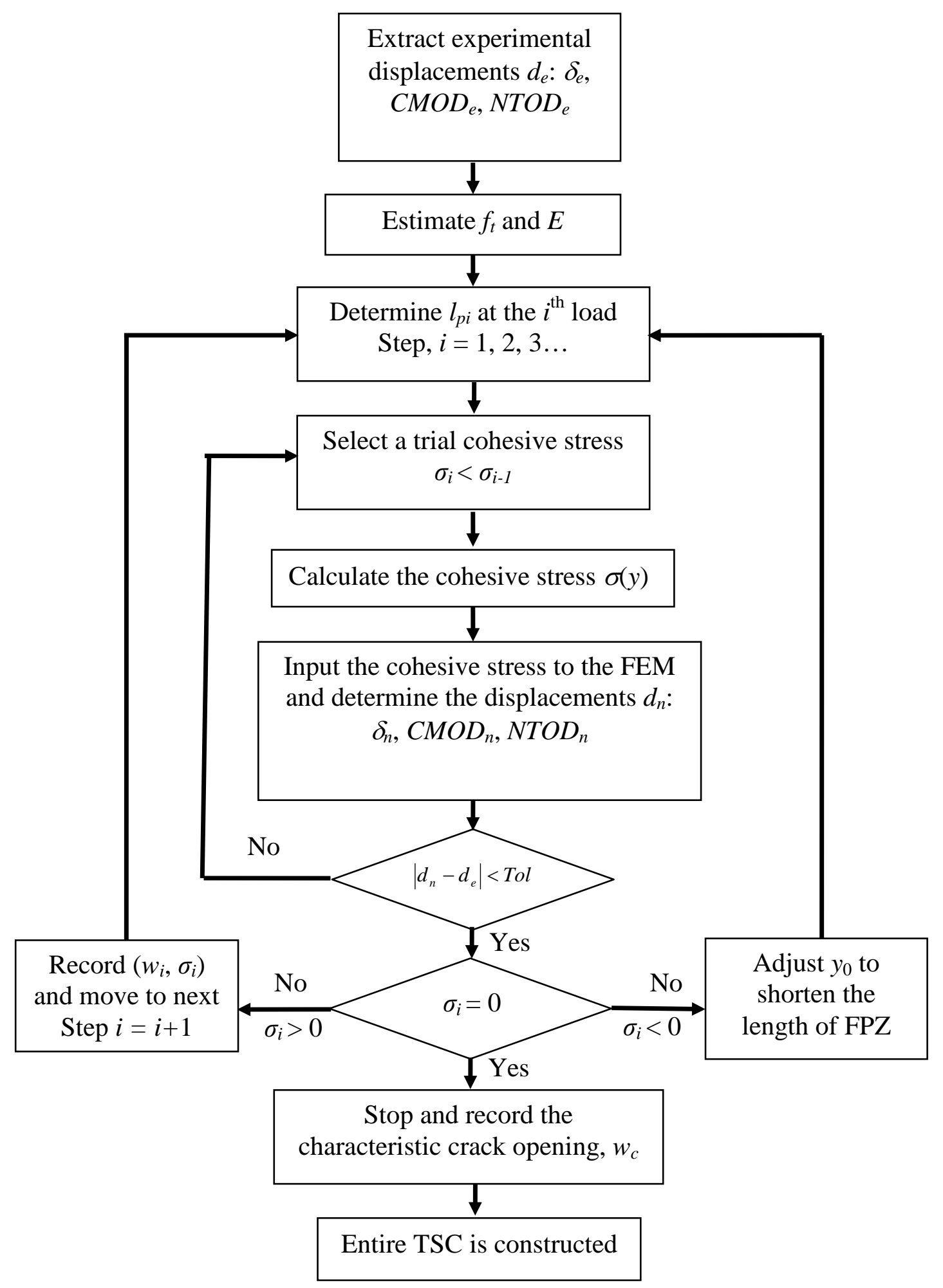

Fig. 3. Flowchart showing the IDCM for TSC evaluation. 


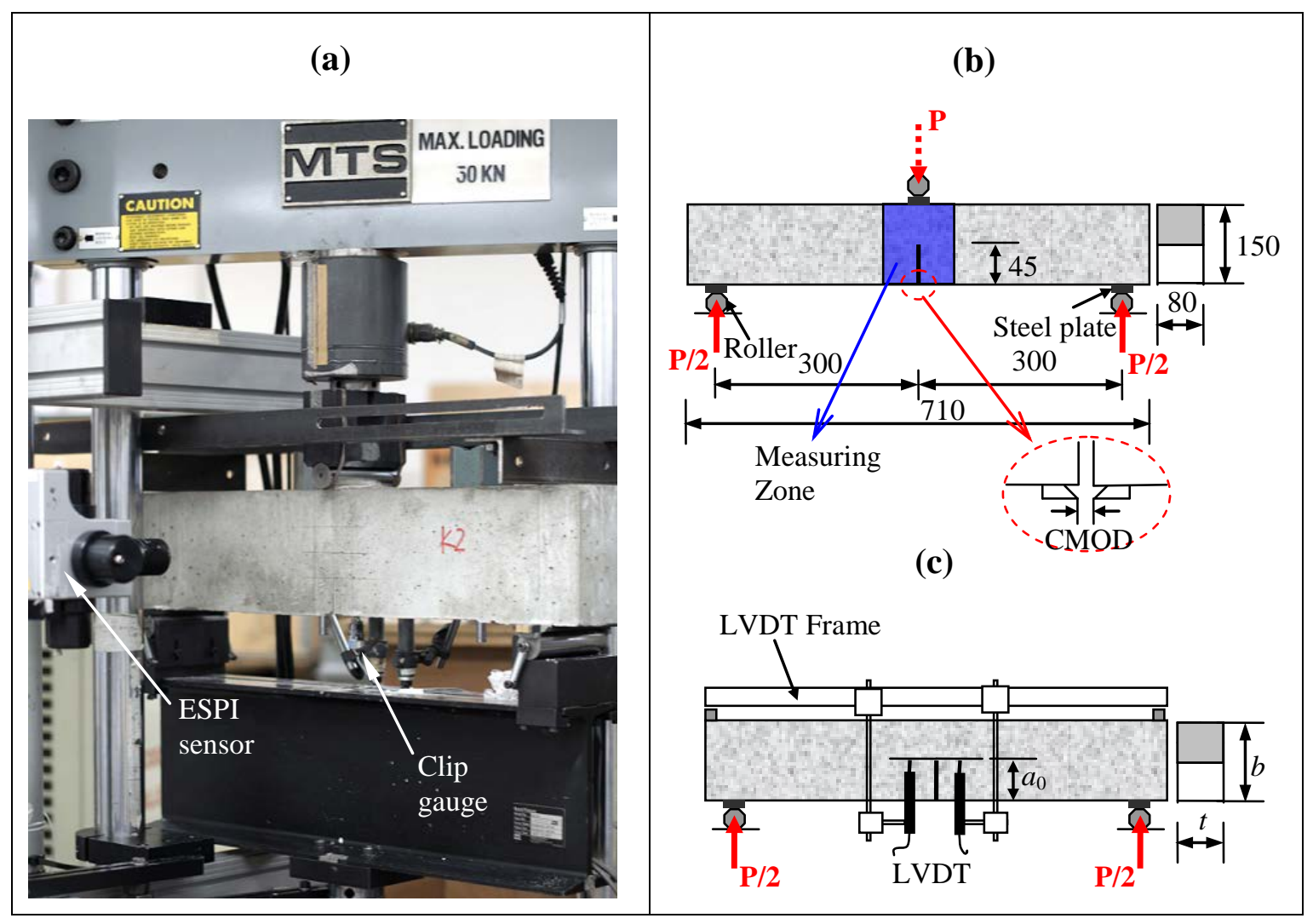

Fig. 4. Experimental setup of three-point bending test: (a) loading and measuring system; (b) schema of front view; (c) schema of rear view.
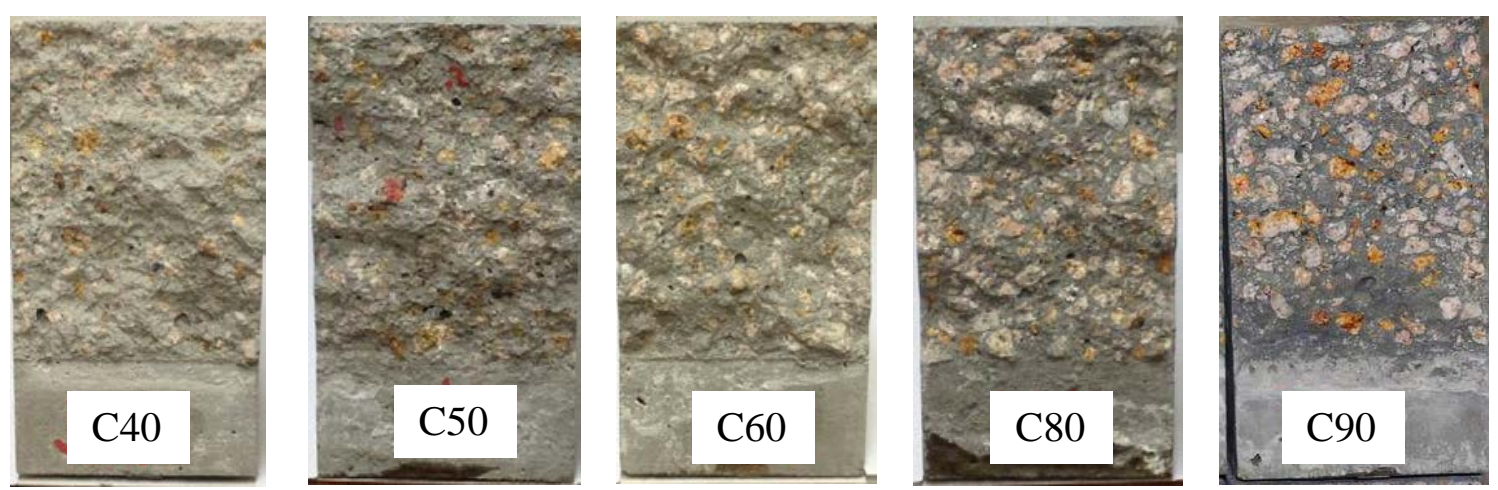

Fig. 5. Planes of rupture of the specimens. 

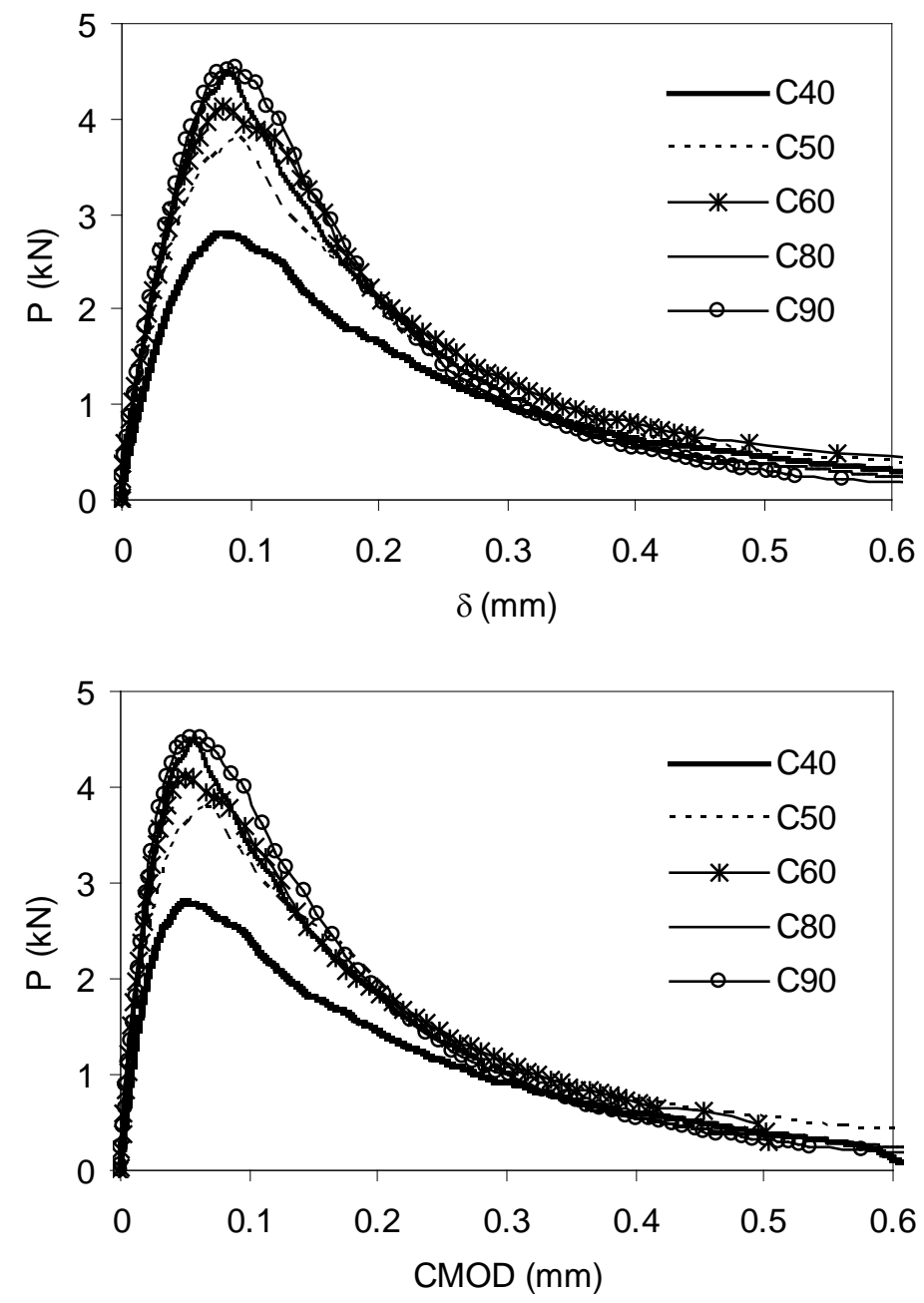

Fig. 6. Experimental load-deflection/CMOD curves for the C40-C90 concrete.
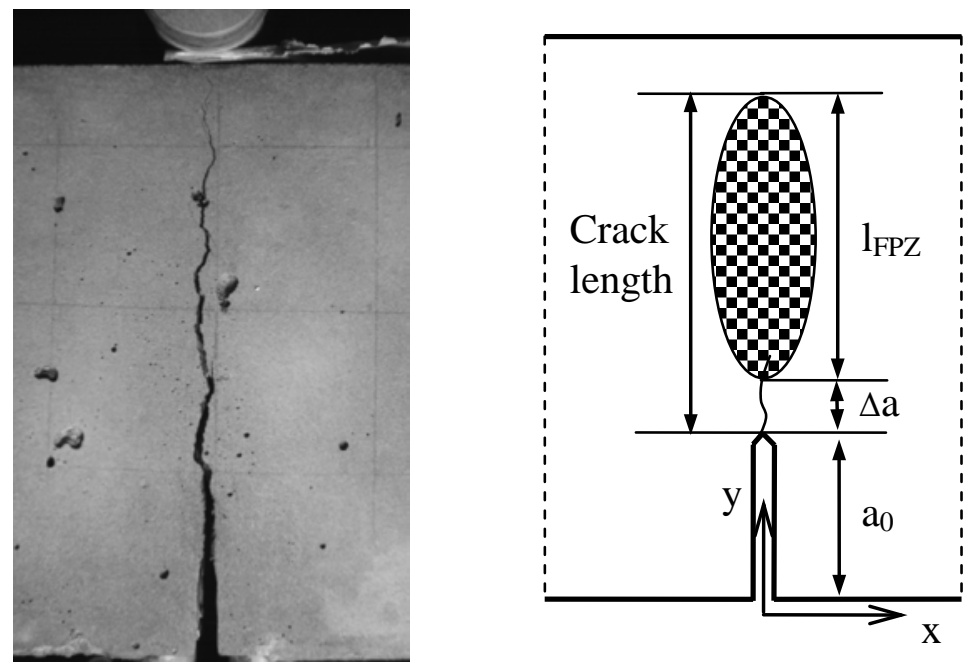

Fig. 7. (a) Crack evolution captured by ESPI sensor; (b) equivalence of the FPZ. 


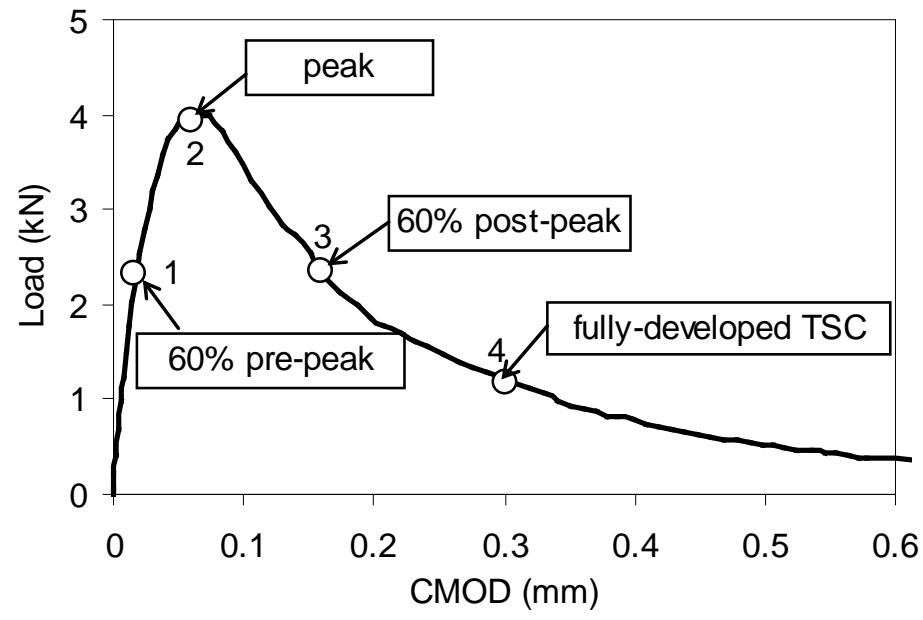

Fig. 8. Four loading stages to be analysed. 

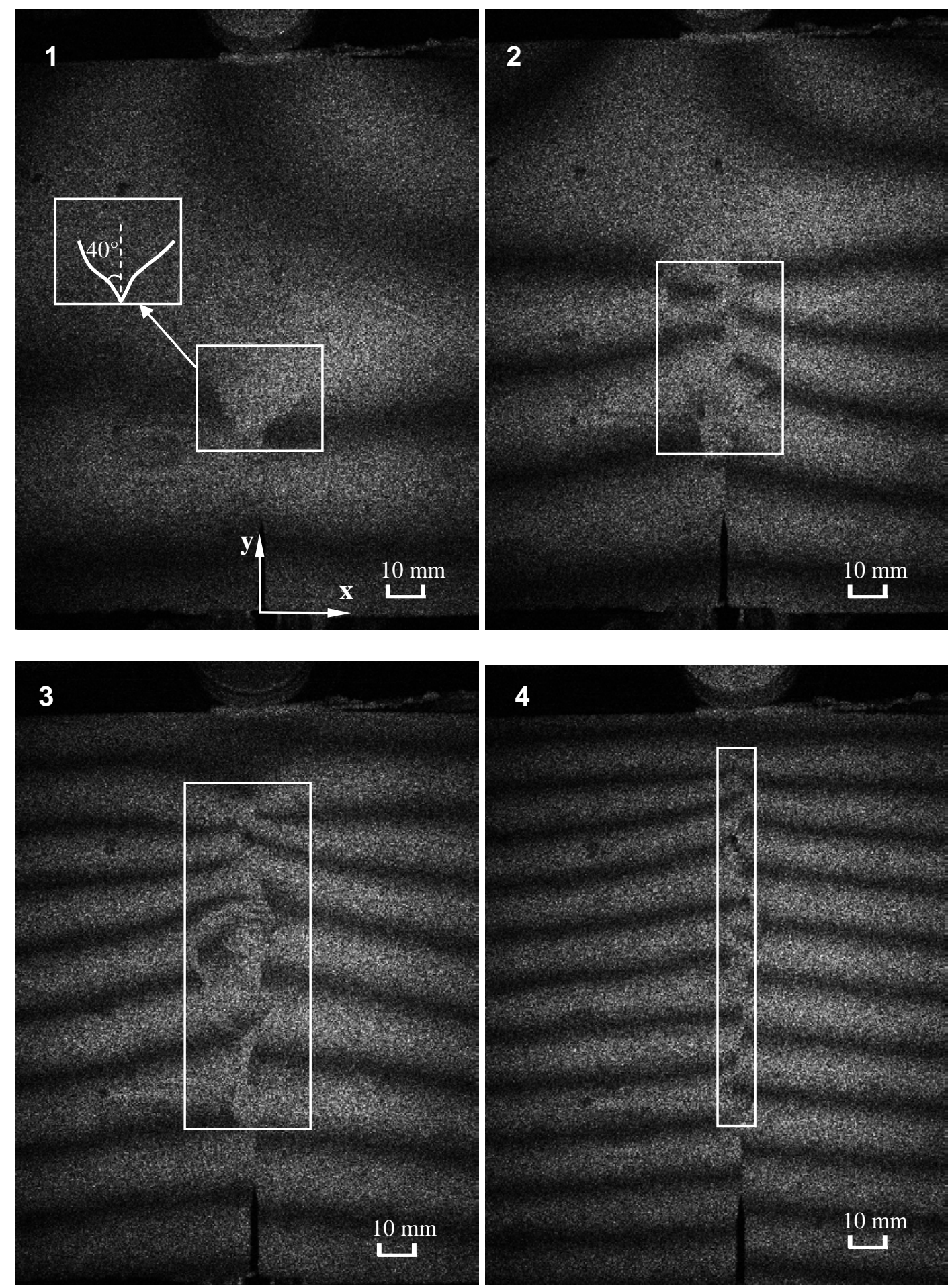

Fig. 9. Fringes at the four loading stages (white boundary represents the FPZ). 


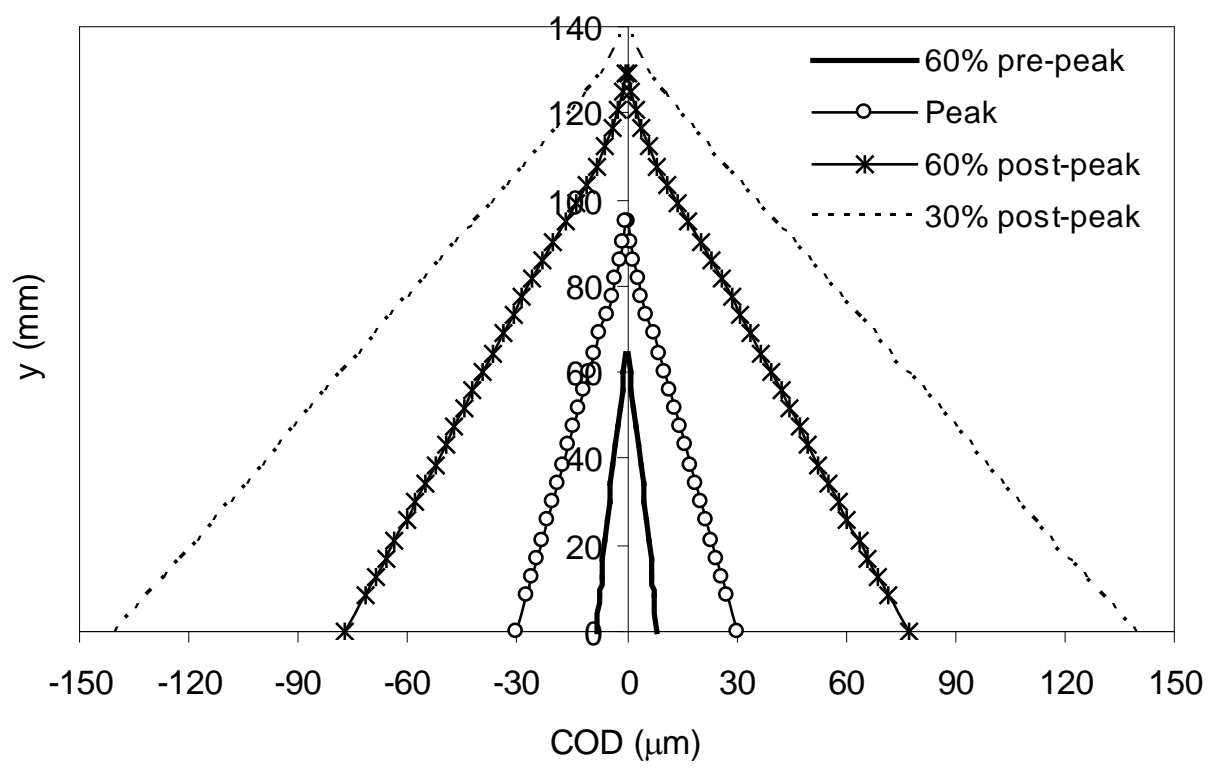

Fig. 10. COD profiles at various loading stages.

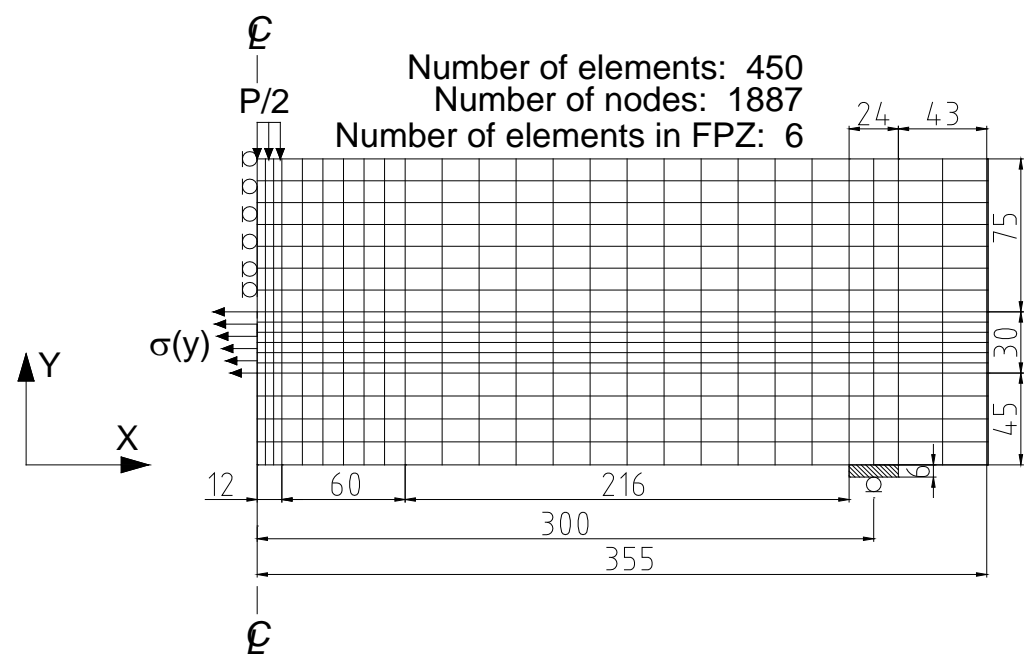

Fig. 11. Specimen configuration and FE meshes (unit: mm). 


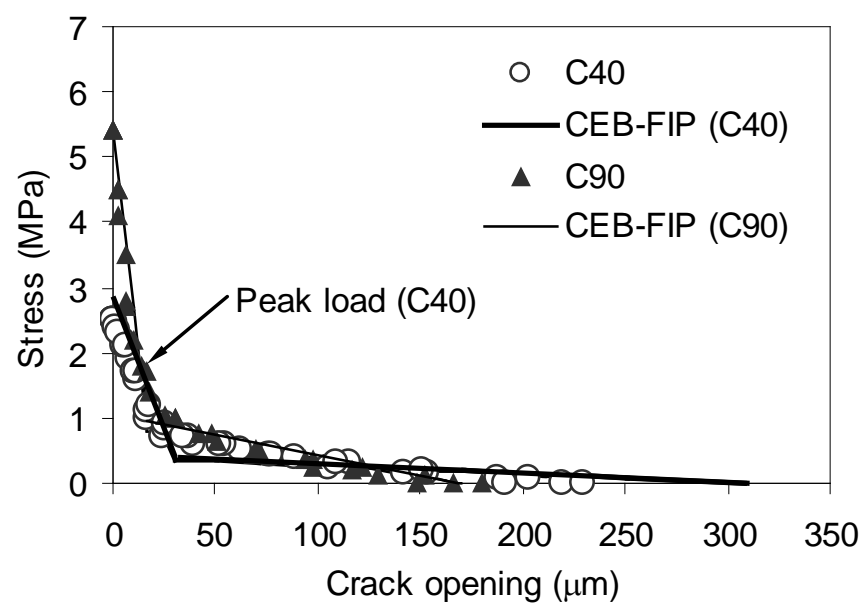

Fig. 12. Comparisons of the estimated TSCs and CEB-FIP model [47].

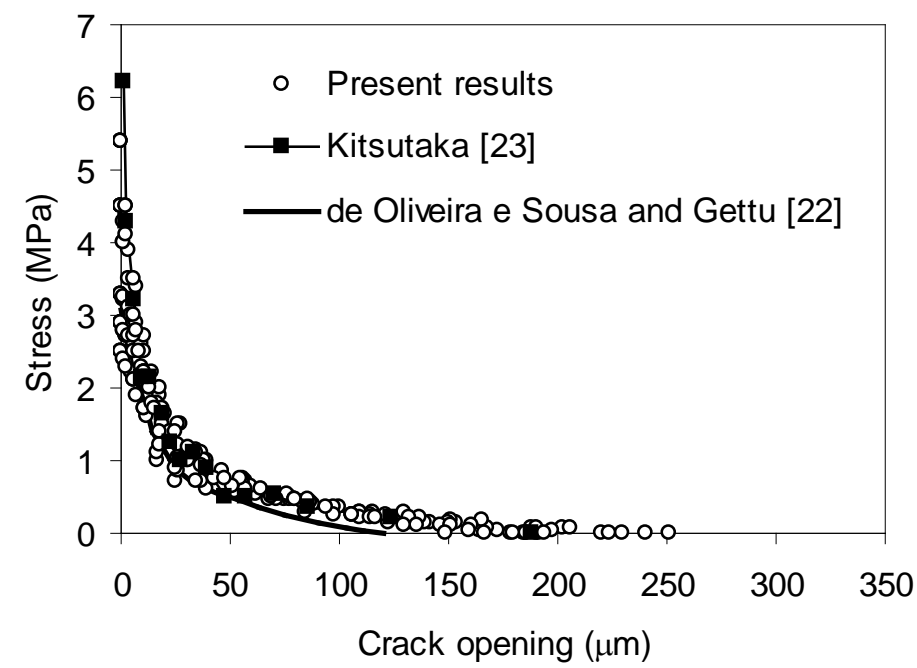

Fig. 13. Comparison of results of this study and previous results. 


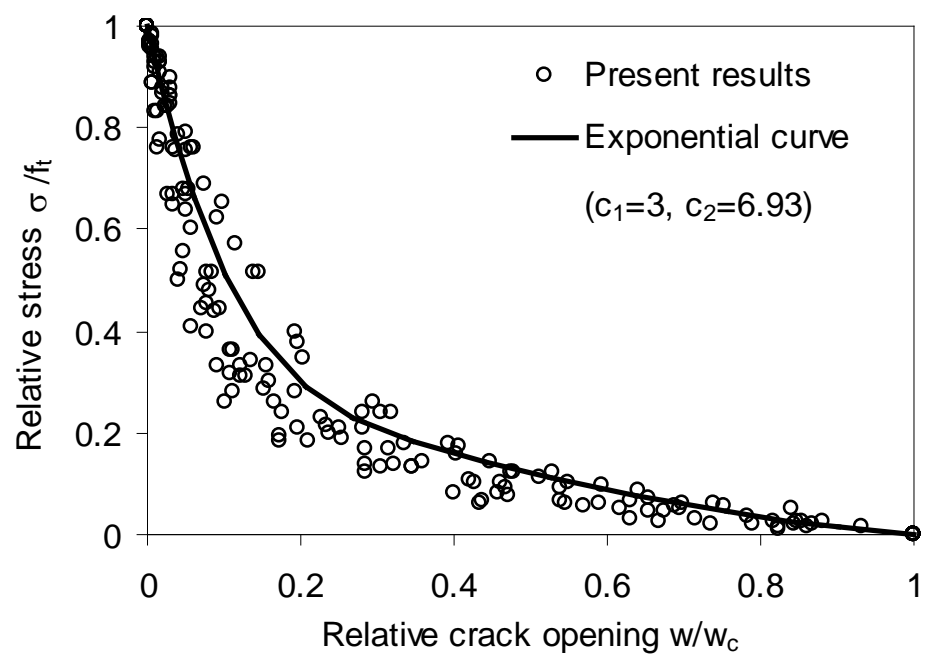

Fig. 14. Comparison of the normalised TSC with the exponential curve proposed by Cornelissen et al. [52].

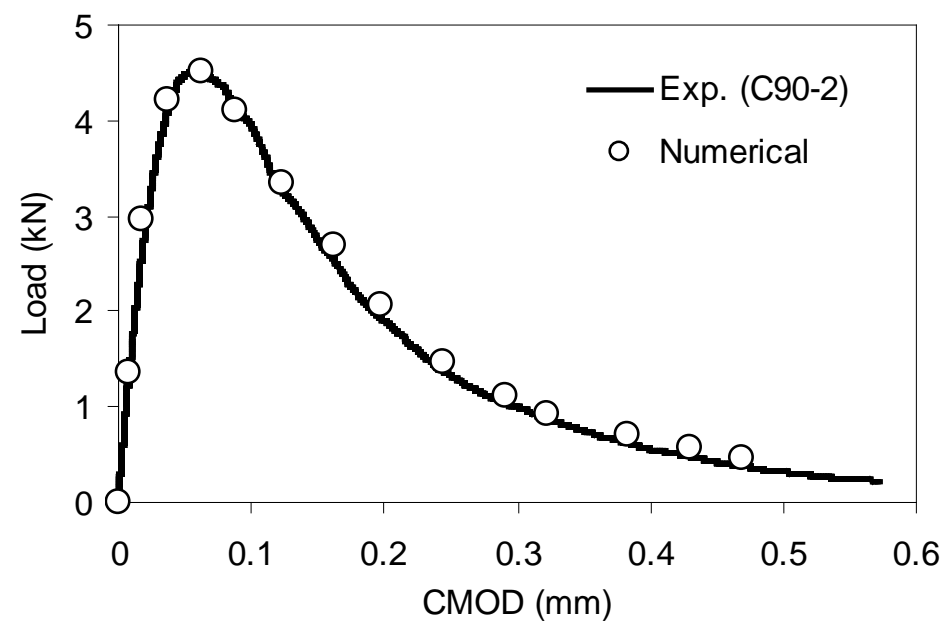

Fig. 15. Comparisons of numerical and experimental load-CMOD curves. 

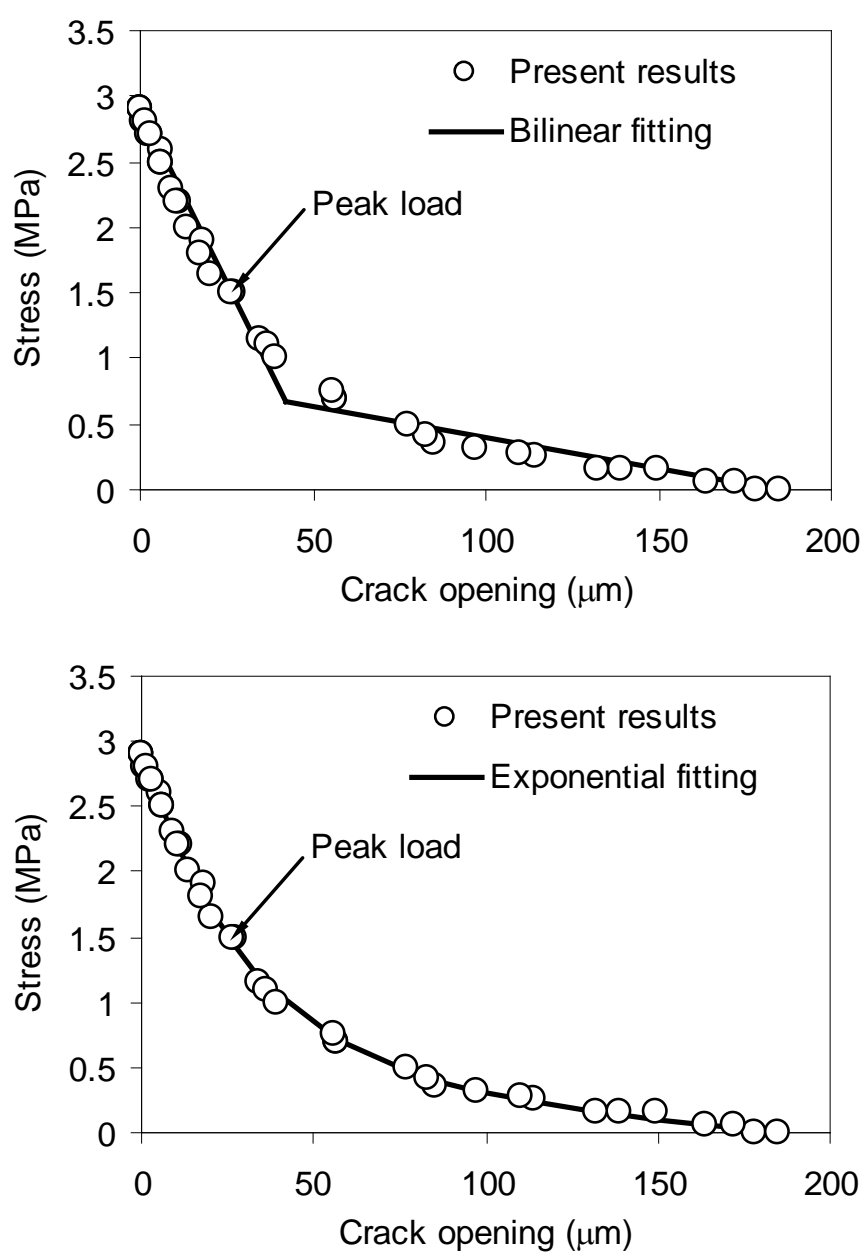

Fig. 16. Approximations of the estimated TSCs: (a) bilinear fitting; (b) exponential fitting.

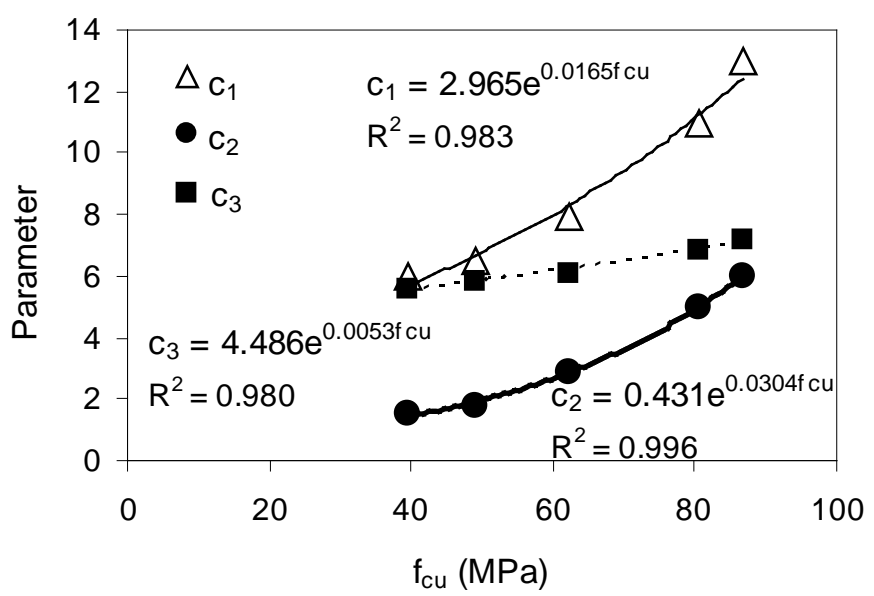

Fig. 17. Relationship between the parameters $\left(c_{1}, c_{2}\right.$ and $\left.c_{3}\right)$ of the exponential curves and $f_{c u}$. 


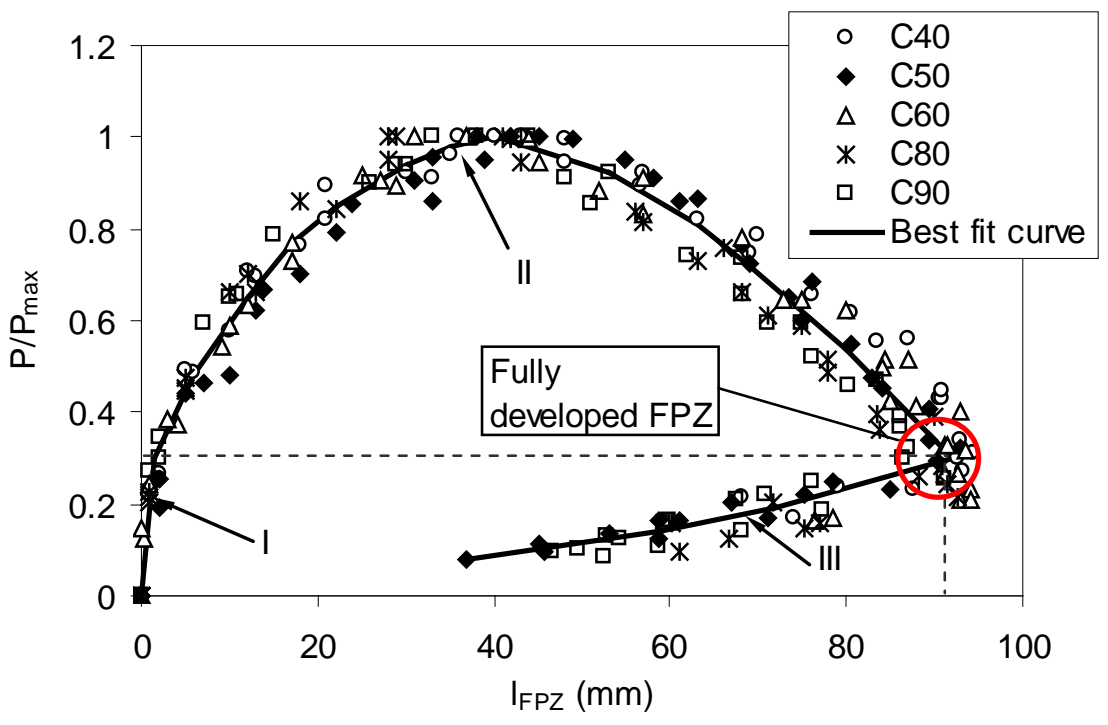

Fig. 18. Relationship between the normalised load and the length of the FPZ. 